\title{
CODE IMPROVEMENT AND MODEL VALIDATION FOR ASCO-II NUCLEAR POWER PLANT MODEL USING A COUPLED 3D NEUTRON KINETICS/THERMAL-HYDRAULIC CODE
}

\author{
R. Pericas ${ }^{1}$, K. Ivanov ${ }^{2}$, F. Reventós ${ }^{1}$, L. Batet ${ }^{1}$ \\ ${ }^{1}$ Universitat Politècnica de Catalunya , Av. Diagonal, 64708028 Barcelona \\ SPAIN \\ Phone +34 934017143 \\ ${ }^{2}$ Pennsylvania State University, 206 Reber Building, University Park, \\ Pennsylvania 16802 USA phone (814)865-0040 \\ raipercas@yahoo.es,kni1@psu.edu, francesc.reventos@upc.edu, \\ lluis.batet@upc.edu
}

\begin{abstract}
This paper provides a Best Estimate validation calculation with a coupled thermal-hydraulic and 3D neutron kinetic model for Ascó-II Nuclear Power Plant. Common NRC codes have been used for its purpose. TRACE is the code used for the thermal-hydraulic system calculations; PARCS is the code used for the 3D neutron kinetics calculations. Cross section calculations were performed with the HELIOS lattice physics code, finally GenPMAXS was used to convert the cross section into the PARCS format. A simplified three dimensional 3D neutronics model of the ASCO II NPP is used as a core kinetics model. A 3D cylindrical thermal-hydraulic vessel plus 1D representation of the remainder of the full plant model is used as the thermal-hydraulic model. The transient selected to ensure the model validation is an actual $50 \%$ Loss of Load. This transient is characterized by space-time effects and was used to validate different thermal-hydraulic system models for the GET university group in the past. The scenario is also good to ensure the validation of a coupled 3D neutron kinetics code since it provides a transient situation between two stable regions at $100 \%$ and $50 \%$. From the current code versions used, some source code modifications have been carried out in order to ensure the correct feedback between thermal-hydraulic and neutron kinetics code. In that sense, a dynamic control rod movement between TRACE and PARCS has been implemented. This is a complete control rod position feedback during transient scenarios. After all the work was performed, the important $\mathrm{TH}$ and NK time trend parameters were compared to the plant data and the comparison was reasonable with some discrepancy, thus the developed system models and the code modifications are robust enough to be used for future safety analysis. New coupled code capability has been tested and found as a required capability, when validating 3D NK-TH coupled calculations.
\end{abstract}




\section{INTRODUCTION}

A validation process of a 3D NK-TH model for Ascó NPP [1] is presented in this paper. The new Ascó-II NPP model for TRACE has been created from the RELAP5 model. TRACE [2] is a TH system code with 3D simulation capabilities. TRACE is coupled to PARCS [3] for reactor physics modeling. HELIOS-1.9 [4] and GenPMAXS [5] were used respectively for cross section generation and conversion into PARCS standard format. The Thermal-Hydraulic Studies Group of the Technical University of Catalonia (GET-UPC) has a long experience in the use of thermal-hydraulic (TH) system codes in the support of plant operation. The group has developed, maintained and improved a RELAP5 model for Ascó-II NPP that has more than twenty years of validated tests for a wide range of transients [7], [8], [9], [10]. The model is a simplified one-dimensional (1D) representation of the plant with a point-kinetics representation of the core neutronics and the core geometry being represented by a single pipe component and two types of heat structures, one for the "hot channel" and the other for the "average channel". Despite the simplicity of the nodalization, the results obtained with this model have shown very good agreement with actual plant data and scaled experimental results. The mentioned model has also been used in several fields of thermal-hydraulic research for the GET group, such as the work performed in the scaling field, see [11] and [12].

The main features of the TRACE-PARCS model as compared to the RELAP5 model are; the $3 D$ representation of the reactor pressure vessel (RPV) and core; the more detailed representation of the core (one heat structure for each fuel assembly); and the introduction of 3D neutron kinetics. A detailed explanation of each model is described in the following sections. Any plant model needs to be validated against actual data. The TRACE-PARCS model of Ascó NPP it is going to be used in a BEPU (Best Estimate Plus Uncertainties) analysis. The model will be also compared against a BE (Best Estimate) analysis and a Conservative analysis, see [13], [14], [15]. The qualification of the model is a step needed to ensure the validity of analyses.

A widely used actual load rejection transient has been selected for the validation. This transient is characterized by time effects and involves several critical plant features such as logics, primary and secondary circuit basic time trends, and power generation. This transient may help validate both the thermal-hydraulic and the neutron kinetics models because of its unique features. Control rod behavior is quite relevant in this transient, since the control rod banks are automatically inserted to achieve the final stabilization. Such control rod movement had been successfully simulated in the validation process of the existing RELAP5 model using the inherent capabilities of the point-kinetics model. In the current TRACE-PARCS code such capability is not enabled. One of the big challenges of the validation has been to ensure the movement of the control rods as a function of the output variables of the involved control system logics.

Validation process was concluded by benchmarking with other models and with plant data. The RELAP5 model is the one that has undergone the most extended qualification process; it has been used in DBA analysis over the last twenty years. It was good when compared to the TRACE point kinetic model, since the thermal-hydraulic model is essentially the same as the TRACE-PARCS model with slight modifications concerning the vessel, core power and heat structures. The validation process against the RELAP5 and TRACE point kinetic models was 
done step by step: first the thermal-hydraulic model is validated (RELAP5 vs. TRACE point kinetics), and thee the PARCS 3D neutron kinetics model is validated.

\section{MODELS}

Nuclear system coupled calculations involve a minimum of two codes: a Neutron Kinetics (NK) code, for simulating the core behavior, and a Thermal Hydraulic (TH) code for the coolant system modeling. PARCS and TRACE are respectively the codes chosen for this study. The models are described in this section.

\subsection{TRACE model}

Ascó NPP is a 3 loop PWR with a thermal power of 2900 MW in its cycle 13 [1]. The TRACE model reproduces completely the whole nuclear steam supply system. TRACE V5 patch2 [2], is the version of the code used in the present study. In a coupled NK-TH code calculation, the most relevant part of the thermal-hydraulic model is the RPV. The 3D cylindrical VESSEL component of TRACE has been implemented to represent the RPV. The vessel model has 15 axial layers, 6 azimuthal sectors and 5 radial rings. The three lower axial levels represent the lower plenum. The next six axial levels represent the active core (central regions), the core bypass, and the down comer (external region). The top layers describe the upper head and the upper plenum of the vessel. Figure 1 shows an axial cut of the vessel representation. The core region consists of 6 axial nodes (layers). Each layer of the axial core region (lighter area) is subdivided into $18 \mathrm{TH}$ cells formed by overlapping three rings and six sectors. Outer rings represent the down comer and the bypass along the active core height. The height of each active core axial node is $0.609 \mathrm{~m}$. The total active core axial height is $3.654 \mathrm{~m}$. Below and above the active core region, the thirty $\mathrm{TH}$ cells formed by overlapping the azimuthal sectors and radial rings represent different volumes of the RPV, as stated above. The rest of the 1D plant model remains typically the same as for a non-coupled system calculation, with a separate representation for each of the three loops. The Main Feed Water and Auxiliary Feed Water systems are modeled for each loop. In terms of the safety injection systems, there are three accumulators, three LPIS and three HPIS systems, the latter six are modeled with FILL components. Finally a control block system with more than 700 components is included, based on our previous RELAP5 Ascó model. The aim of the control block system is to reproduce accurately the plant response to different transients. Table 1 shows the $\mathrm{TH}$ model specifications in terms of the quantities used for the components. 


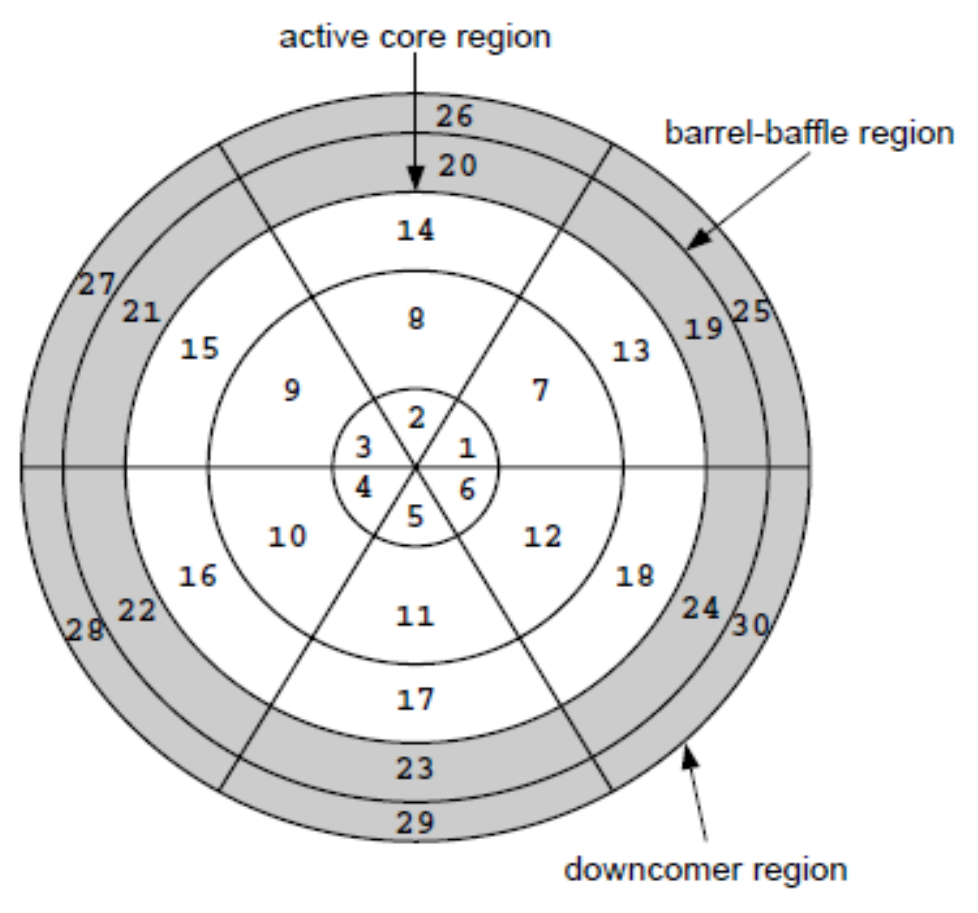

Figure 1. Axial layout of the TRACE vessel model

Table 1. TH model specifications

\begin{tabular}{|l|c|}
\hline \multicolumn{1}{|c|}{ Component } & Quantity \\
\hline Fills & 7 \\
\hline Breaks & 16 \\
\hline Pipes & 94 \\
\hline Pumps & 3 \\
\hline Separators & 3 \\
\hline Single junctions & 15 \\
\hline Valves & 19 \\
\hline Vessels & 1 \\
\hline Control systems & 1455 \\
\hline Heat structures & 175 \\
\hline $\begin{array}{l}\text { Power } \\
\text { components }\end{array}$ & 162 \\
\hline
\end{tabular}

\section{$1.2 \quad$ PARCS model}

Ascó NPP core neutronics is modeled with PARCS v3.0 [3]. Each of the 157 fuel assemblies (all with a $17 \times 17$ pin array) is represented by one node in the radial plane which, by adding 
64 radial reflector nodes, sums up to 221 radial nodes per axial level. Axially the fuel region is divided into $24+2$ nodes, 24 for the core active region and 2 for the bottom and top reflectors. The height of the nodes is large in the central region and smaller in the lower and upper regions, in order to reproduce accurately the flux and thus the cross-section variation along the core length. In terms of the cross-section library, considering the different types of fuel and burn-ups, and the 6 control rod banks, $648+2$ different compositions result. The cross-section library, containing two-group cross sections, has been generated with the lattice physics code HELIOS-1.9 [4] using plant specifications for cycle 13 [1].

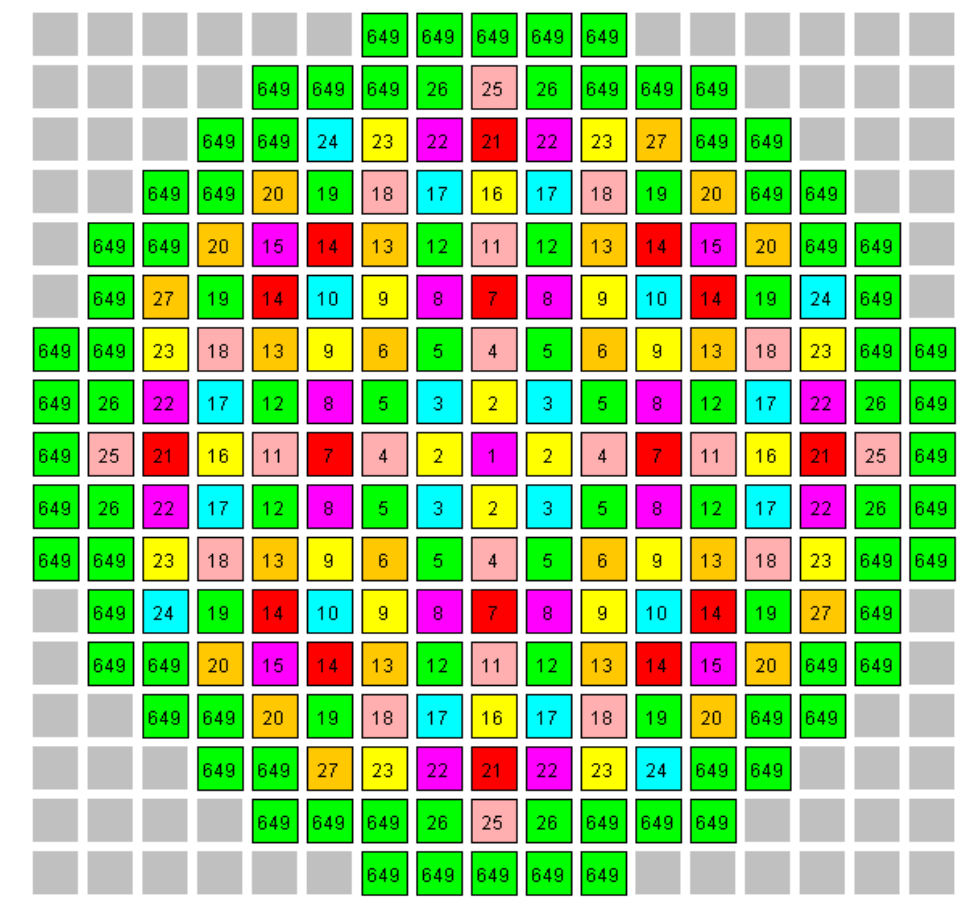

Figure 2. Radial core assembly layout at axial plane 2

Figure 2 shows the radial distribution of the fuel assemblies (FA) in the core. Note that there are 27 different types of FA with different enrichments, from $2.1 \%$ to $4.55 \%{ }^{235} \mathrm{U}$. Also the newest FA contains burnable absorbers, with varying $\mathrm{Gd}_{2} \mathrm{O}_{3}$ concentration from $2.0 \%$ to $8.0 \%$ depending on the FA. Each FA has 264 fuel pins plus 25 Guide tubes. All the crosssections have been generated as a function of moderator temperature, fuel temperature, moderator density, boron concentration and the insertion of control rods. The ranges of the thermal-hydraulic feedback parameters have been selected in order to cover both initial steady-state and expected transient conditions.

\subsection{Coupled model}

The thermal hydraulic model has been set up to meet the requirements of the neutronics model. There are 157 Heat Structures (HS) in the core region, each one representing one FA. There are 18 radial thermal-hydraulic cells in each axial thermal-hydraulic layer in the core region. Figure 3 shows the assignment (mapping) in a radial plane, of the active core and reflector $\mathrm{TH}$ cells to the neutronics nodes. Every different color area represents a thermal-hydraulic cell. In terms of the axial nodalization, the 24 non-equidistant axial nodes of the neutronic model are equivalent to those of the HS; however, only 6 equidistant nodes 
exist in the hydraulic model. Consequently the axial mapping between the HS nodes and each neutronic node is one to one, whereas several neutronic and HS nodes are linked to one single thermal-hydraulic node. So, several neutronic nodes are receiving the same thermal-hydraulic information whereas, one thermal-hydraulic node is receiving averaged power information from different neutronic nodes.

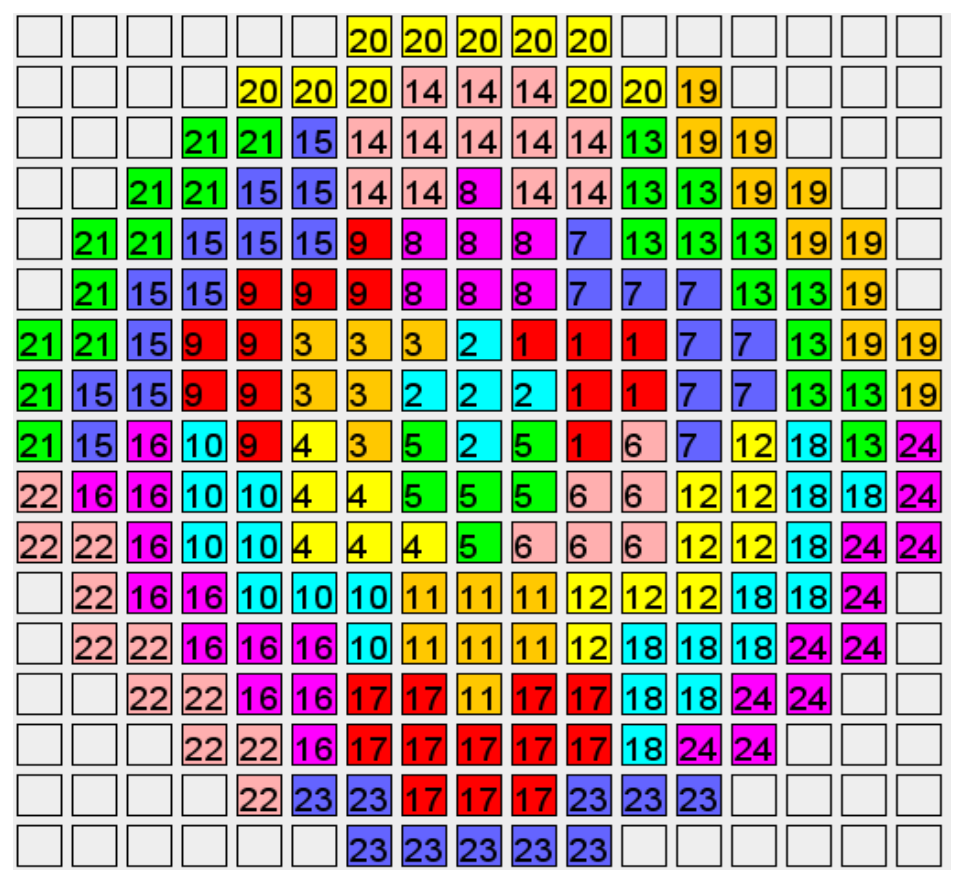

Figure 3. Core neutronics and HS nodes mapping to TH cells.

\section{DYNAMIC CONTROL ROD MOVEMENT IMPLEMENTATION IN TRACE/PARCS}

The transient selected for code validation (a 50\% load rejection) involves the automatic movement of the control rod banks. The code versions used, TRACE v5.0 patch2 [2] and PARCS 3.0 [3] did not allow the movement of the control rods as a result of the reactor control logics. In previous analyses the control rod position had to be pre-assigned by means of a table in terms of position vs. time. In order to simulate the automatic movement of the control rods, the TRACE and PARCS source codes have been modified. Different analyses have been performed in this field using different coupled codes [16]. A similar task was performed in [16] with RELAP5/PARCS $\vee 2.7$ which preceded the work reported in this paper using the TRACE/PARCS coupled code. With the modifications, the position of each PARCS control rod bank is made dependent on TRACE's control variable output. Several tests have been performed to ensure the code is able to run normally with the implemented modifications, and that none of the previous capabilities has been disabled. Once the code modifications were tested, a control system was implemented in the TRACE model which checks the different parameters from the simulated plant and computes the control rod banks position (inserted steps) every time step. Even the scram signal is now controlled by TRACE. At each time advancement step, the information of the inserted steps for each of the control rod banks is conveyed to PARCS. With these modifications, the new compiled code has the capability of dynamic control rod movement and the coupled TRACE/PARCS model is ready to be validated. 


\section{3. $\quad 50 \%$ LOSS OF LOAD EVENT DESCRIPTION}

The $50 \%$ load rejection transient chosen for the analysis was performed as a start-up test of Ascó-II at the beginning of cycle 13, in 1999. The initiating event is a manual turbine load reduction from $100 \%$ to $50 \%$ at $200 \%$ /min maximum rate. There is no other manual action apart. Table 2 shows the time of occurrence of the main events. There are no boundary conditions imposed on the model, since the validation of the model is perceived to be achieved at the end of the calculation. It is expected that all the plant systems behave properly using the new model in order for it to be validated.

Table 2. 50\% loss of load main events time trends

\begin{tabular}{|c|c|}
\hline Time [s] & Event \\
\hline 0.0 & Manual turbine load reduction \\
\hline 8.0 & Steam dump valves open \\
\hline 14.0 & Pressurizer spray's maximum value \\
\hline 26.0 & Pressurizer spray off \\
\hline 761.0 & Pressurizer spray start-up \\
\hline 1000.0 & End of transient \\
\hline
\end{tabular}

Data from the real $50 \%$ loss of load scenario are shown in comparison with results from the coupled calculation. Figure 5 illustrates the total nuclear power time trend: power decreases from a steady full power situation and stabilizes again at 50\% of the total power. Figure 6 shows the control rod bank D movement (this bank is the first to be inserted in the core). The evolution of the pressurizer pressure along the transient is displayed in Figure 7 . The evolution of other interesting parameters is plotted in figures 8 to 11: pressurizer water level, secondary pressure and flow rate in one steam generator, and the average core temperature. The figures selected in this section are sufficient to illustrate the transient; nevertheless other relevant parameters in other to validate the model are plotted in the following sections.

\section{ASSUMPTIONS OF THE MODEL}

All the safety systems are postulated to function properly in the present study as it was expected in the plant during the tests. Beginning of life conditions for the core kinetics parameters were selected [1], according to the situation of the plant. There is no recorded information on pressurizer heater behavior. For the analysis it was assumed that fixed heaters 1 and 2 remain on during the transient. Heat from these heaters is compensated by the partial opening of the pressurizer spray valves.

\section{STEADY STATE CALCULATION}

To execute a transient calculation, several steps prior to the calculation are required. The first step is to run a steady-state TRACE standalone calculation (i.e. using only the thermal 
hydraulic model, with the power imposed by an input table) to stabilize the plant flow parameters. The second step is a coupled steady state calculation, restarting from the previous calculation, with the 3D neutron kinetics code in steady state mode. As a result, all the parameters affecting neutron kinetics (fuel and moderator temperature, boron density and moderator density) are taken to have 0.0 reactivity at full power. Coupled full plant stabilization is the objective of this calculation. Once all the plant parameters are in steadystate, both codes are run in transient mode. In this calculation a short null transient has been run before enabling the actuation of the control rod positioning system, so as to ensure that the power computed in transient mode is also stable as in steady state conditions. At the end of the null transient, the control rods position in the model is slightly different than in the plant; nevertheless, this fact does not noticeably affect the performance of the model during the transient, since the reactivity of the control rods is quite small when they are only inserted a few steps. This difference is attributed to the cross section library calculation and the information exchange between the two codes. Table 3 shows a comparison between calculated values and the plant steady state values. Also a percentage deviation from the plant value is presented.

Table 3. Steady state values

\begin{tabular}{|l|c|c|c|c|}
\hline Quantity & Plant value & $\begin{array}{c}\text { Calculated } \\
\text { value }\end{array}$ & Units & $\begin{array}{c}\text { Deviation } \\
\text { over plant } \\
\text { data (\%) }\end{array}$ \\
\hline Nuclear power & 100.28 & 98.77 & $(\%)$ & 1.51 \\
\hline Turbine power & 99.95 & 99.34 & $(\%)$ & 0.61 \\
\hline Reference temperature & 579.58 & 580.30 & $\mathrm{~K}$ & 0.12 \\
\hline Mean temperature & 579.75 & 579.86 & $\mathrm{~K}$ & 0.02 \\
\hline Pressurizer level & 56.69 & 55.12 & $(\%)$ & 2.77 \\
\hline Primary pressure & 15520136 & 15534774 & $\mathrm{~Pa}$ & 0.09 \\
\hline Secondary pressure & 6560923 & 6435991 & $\mathrm{~Pa}$ & 1.90 \\
\hline Bank D with drawn steps & 214 & 208 & $\mathrm{steps}$ & 2.80 \\
\hline SG1 narrow level & 50.56 & 53.04 & $(\%)$ & 4.91 \\
\hline SG2 narrow level & 50.56 & 51.62 & $(\%)$ & 2.09 \\
\hline SG3 narrow level & 50.54 & 51.66 & $(\%)$ & 2.23 \\
\hline $\begin{array}{l}\text { Steam mass flow secondary } \\
\text { loop 1 }\end{array}$ & 535.94 & 538.71 & $\mathrm{~kg} / \mathrm{s}$ & 0.52 \\
\hline $\begin{array}{l}\text { Steam mass flow secondary } \\
\text { loop 2 }\end{array}$ & 539.16 & 531.27 & $\mathrm{~kg} / \mathrm{s}$ & 1.46 \\
\hline $\begin{array}{l}\text { Steam mass flow secondary } \\
\text { loop 3 }\end{array}$ & 537.34 & 528.54 & $\mathrm{~kg} / \mathrm{s}$ & 1.64 \\
\hline
\end{tabular}

\section{TRACEIPARCS RESULTS}

Once the steady state conditions are reached, a transient analysis is performed. After a preliminary analysis, some inaccuracies in the model output were identified, especially regarding the control rod position. A delay on the control rod movement was identified as one source of uncertainties in the problem. The phenomenon was detected and isolated, and 
several causes were identified as triggers of the discrepancies: coarse TH nodalization, malfunction in TRACE/PARCS information exchange; wrong PARCS behavior when control rod insertion velocity is low; and finally, XS set bad prediction. Two results are compared with the plant data in this section: TRACE/PARCS XS1 and XS2. Acronym XS1 identifies the original cross section sets whereas XS2 identifies a modified set with modified absorption coefficients. In order to reduce the control rod position discrepancies, the absorption cross section coefficients have been modified by increasing their original computed value by $10 \%$. The comparison is useful to illustrate how some deficiencies in the cross section set can cause a large discrepancy of the coupled calculations predictions. The authors agreed to use the modified cross section set due to the fact that more accurate results were shown after the modification. The cross section modification was determined using the authors experience in neutron kinetics and BEPU calculations. Besides that issue, the other TH values are fitting reasonably well to the plant data. Plots in this section compare the results obtained with TRACE/PARCS model to plant data. Total power time trend can be seen in Figure 5. Figure 6 shows the position of the control rod of bank D, which is the first one to be inserted in the core. In Figure 7 and Figure 8 pressurizer pressure and water level are compared to plant data. Secondary side main features are compared in Figure 9 and Figure 10; the former shows the SG2 pressure evolution and the latter the vapor production rate. A small deviation in the initial secondary side pressure results from a gap between measured and computed values. Results of the other loops, not represented here, show the same agreement with plant data for these parameters. Figure 11 illustrates the good behavior of the average temperature in the loops.

In order to assess the ability of the PARCS 3D kinetics model to capture the radial power distribution, a steady-state comparison is made in Figure 12 between the TRACE/PARCS prediction and the data supplied by the core designed [1]. In Figure 13 the percentage of each FA relative deviation between both sets of data is shown. The average deviation is $\pm 5.86 \%$. Summarizing, it can be stated that there is a fair agreement between the model and the plant data. Some small differences can be explained by the nodalization approximation of the model. 


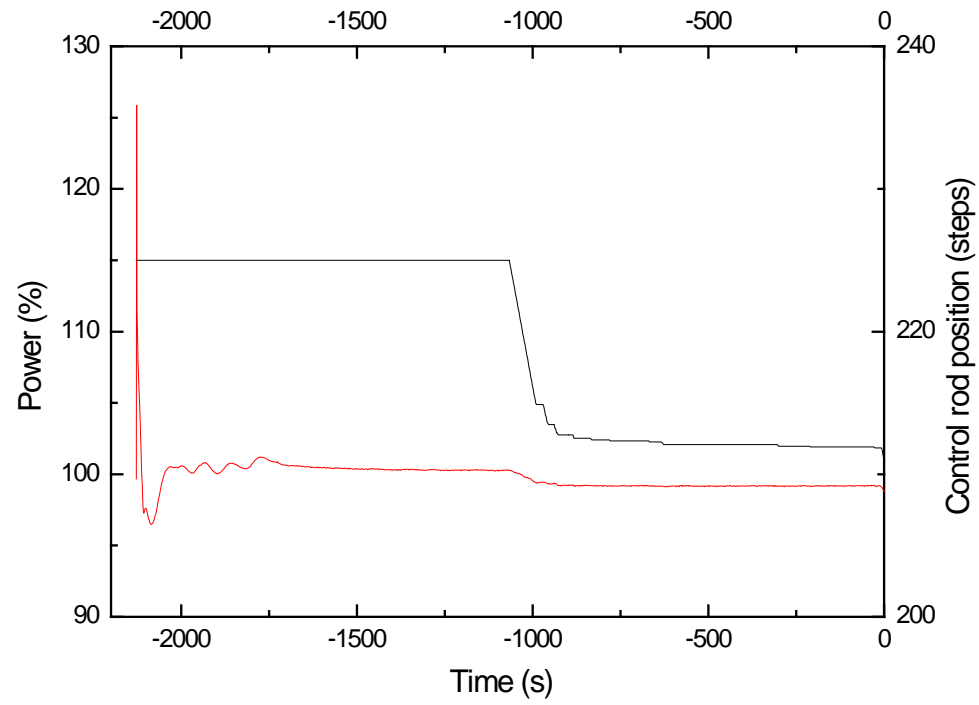

Figure 4. Control rod steady state adjust position

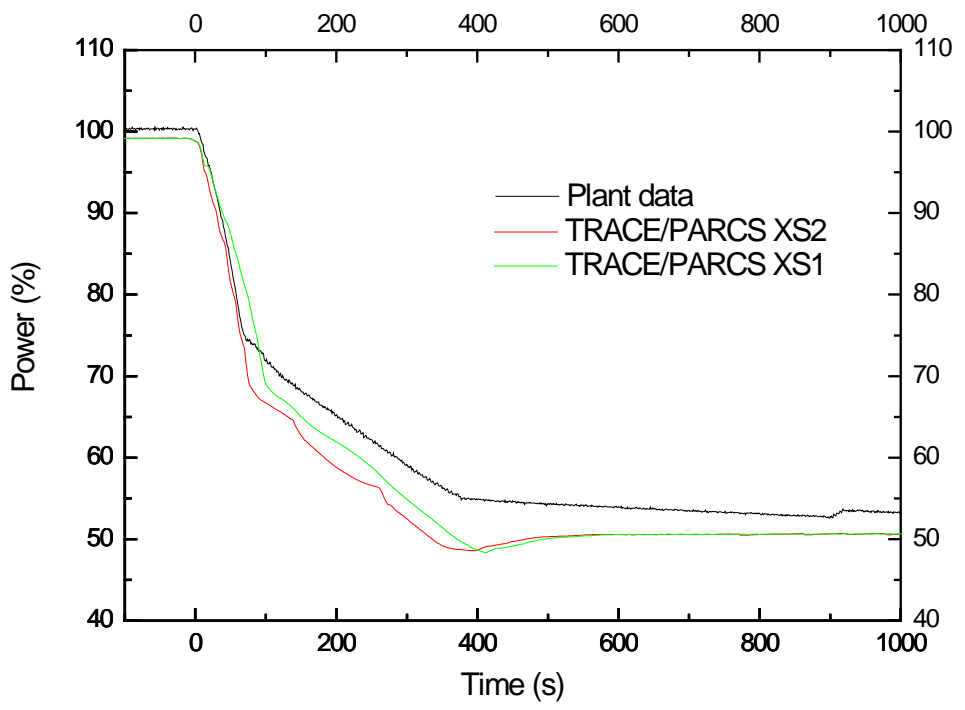

Figure 5. Total power TRACE/PARCS vs plant data 


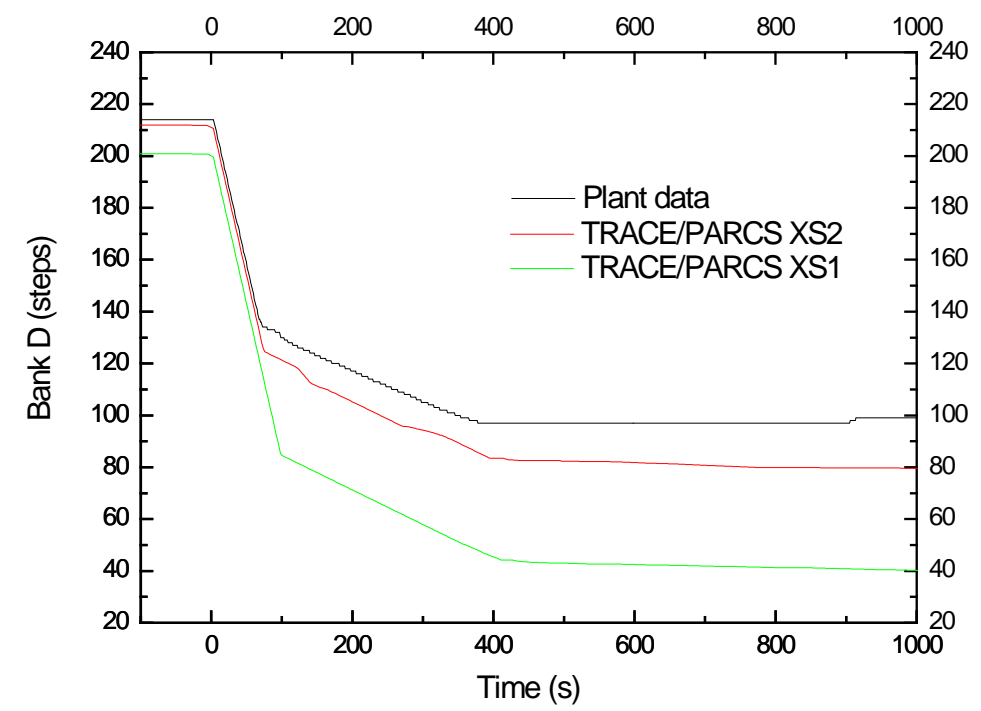

Figure 6. Control rod bank D TRACE/PARCS vs plant data

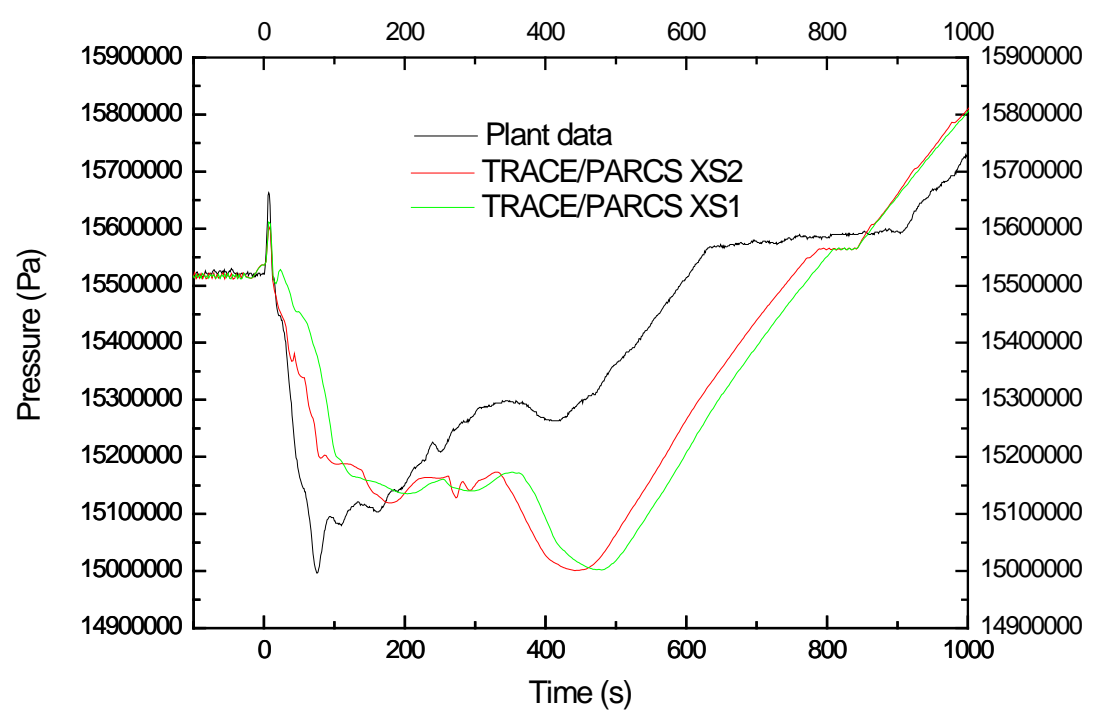

Figure 7. Pressurizer pressure TRACE/PARCS vs. plant data 


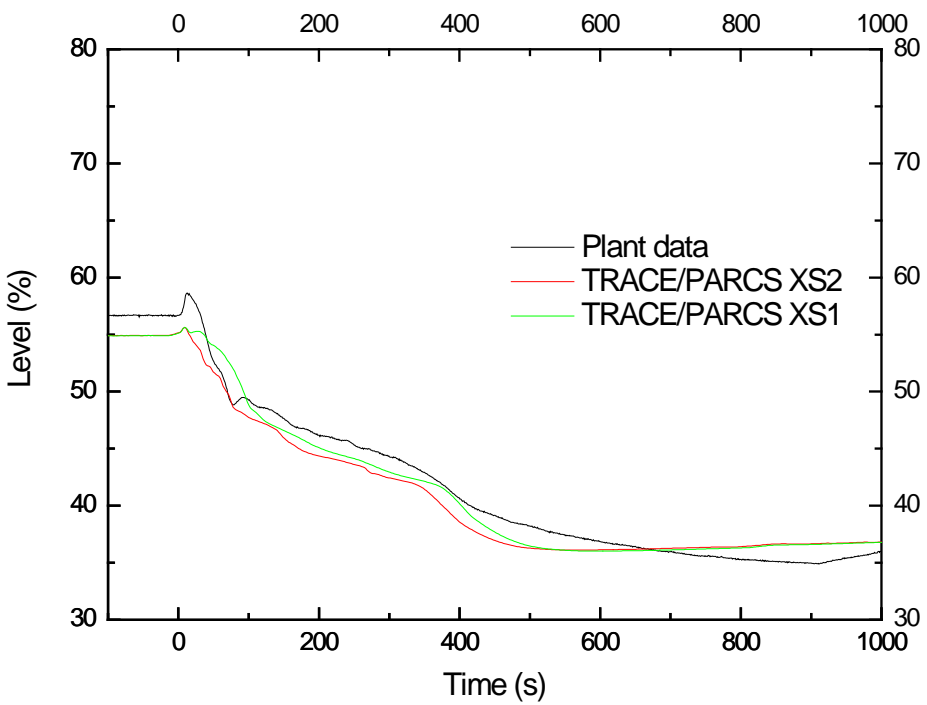

Figure 8. Pressurizer water level TRACE/PARCS vs plant data

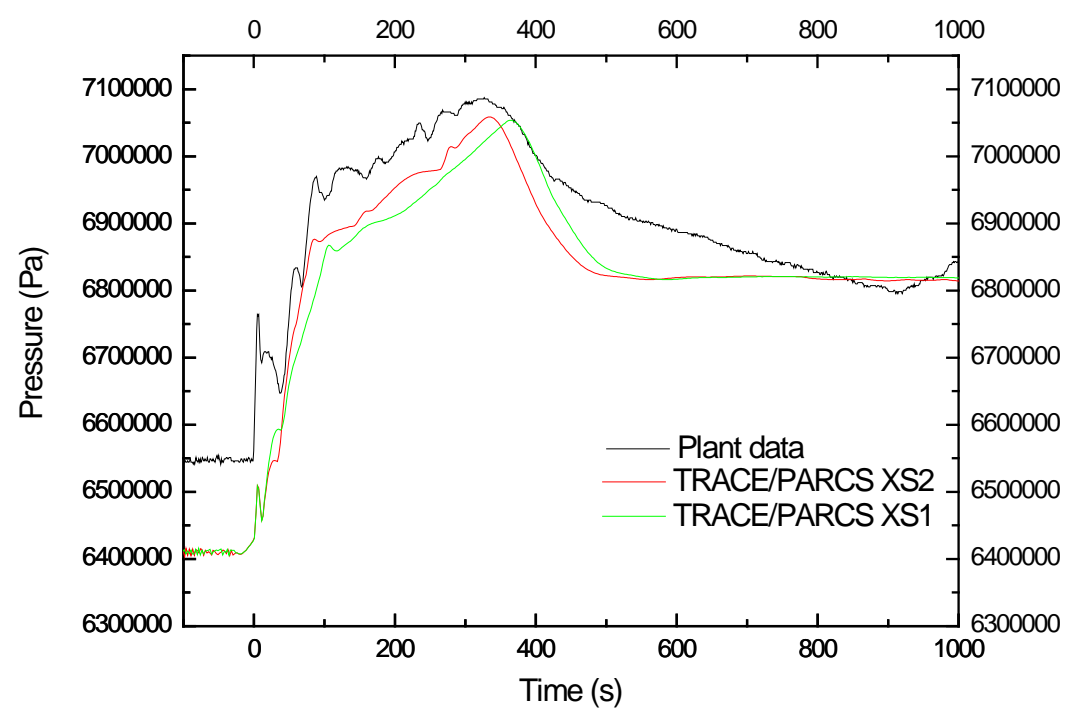

Figure 9. Secondary side SG2 pressure TRACE/PARCS vs plant data 


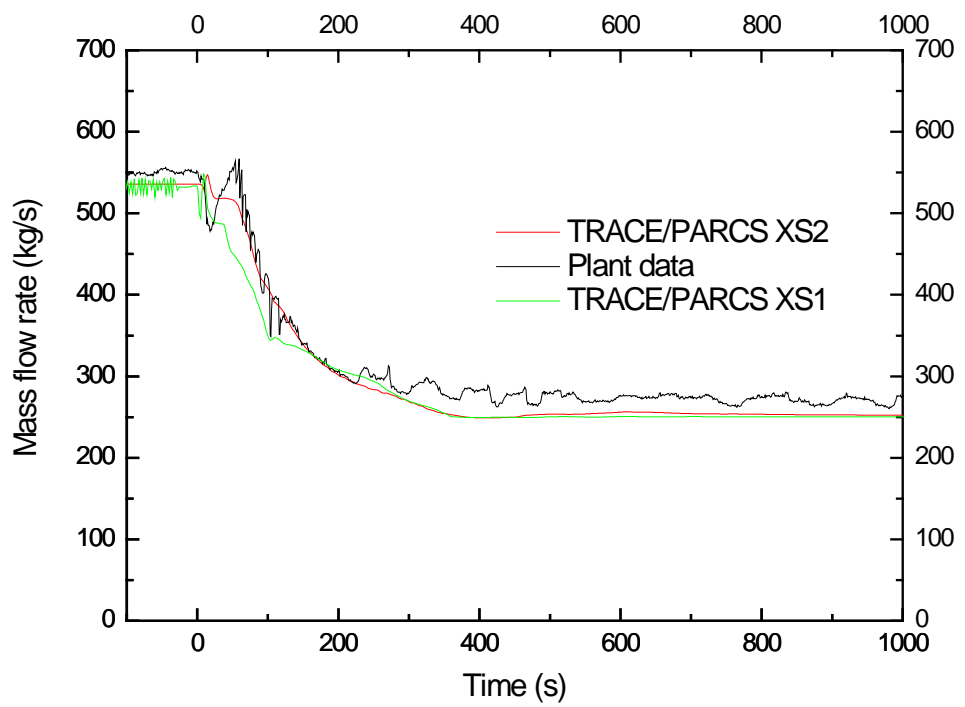

Figure 10. Secondary side SG2 vapor mass flow TRACE/PARCS vs plant data

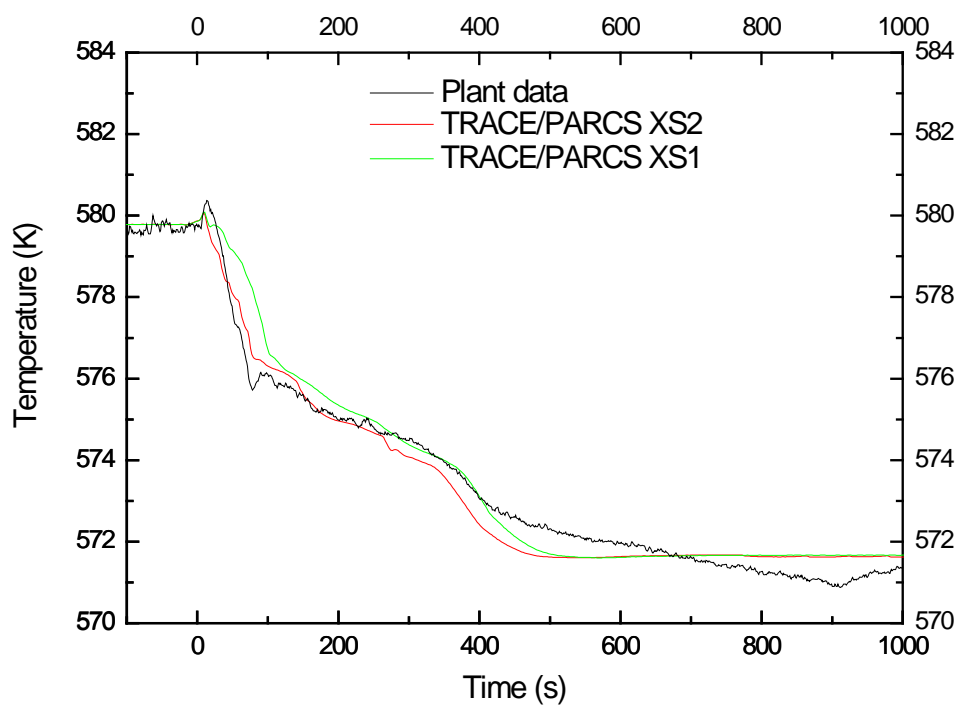

Figure 11. Loops mean temperature 


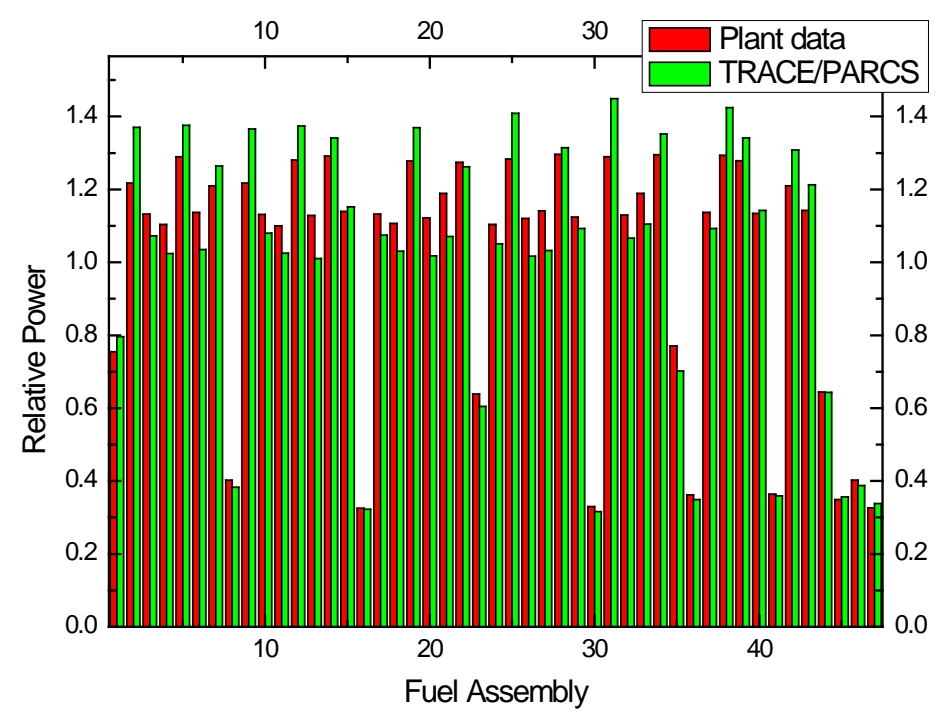

Figure 12. XS2 radial fuel assembly comparison

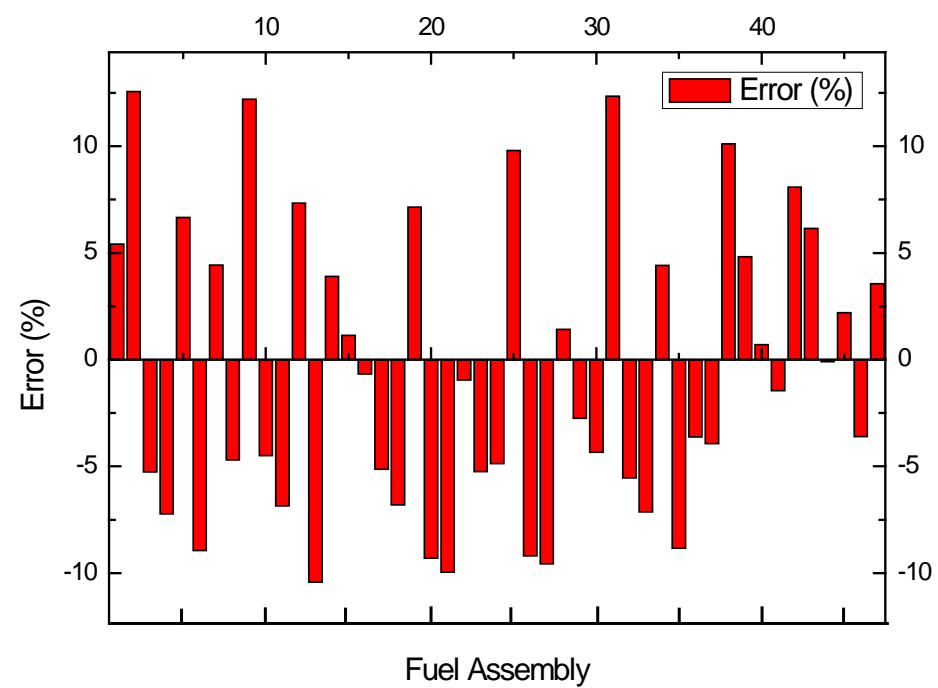

Figure 13. XS2 (\%) Error radial fuel assembly comparison

\section{COMPARISON OF MODELS AND CODES}

TRACE/PARCS results were next compared with other computational results. Three different calculations are benchmarked. Results of the TRACE/PARCS 3D kinetic model are compared with TRACE and RELAP5 point kinetic calculations. While TRACE point kinetics model is quite new and poorly validated, RELAP5 model has been used for more than twenty years; a large library of plant transients has been compiled during this time: the model shows a very good agreement with the plant data in a wide range of conditions and scenarios. The 
comparison will provide meaningful information on the quality of the developed model. Total power time trend is compared in Figure 14; here TRACE/PARCS and RELAP5 behave similarly. Deviations from plant data is observed in the prediction of the control rods position, Figure 15. Such discrepancies are attributed to the cross section library accuracy and also to the information exchange coding from TRACE/PARCS, more investigation needs to be done in this area, the conclusions section gives a list of improvements and fields of study in order to test and correct this issue. Pressurizer parameters are compared in Figure 16 and Figure 17. Very good agreement is seen in terms of the pressurizer level but some discrepancies are detected in pressure time trends. Such differences are attributed to the degree of detail in the pressurizer control logic also to the malfunction of the pressurizer heaters in the coupled calculation; again some research over the source code needs to be performed here. Also these discrepancies are thought to be related to some unrecorded manual actions, such as valve operation, that were performed at the end of the transient and that have not been simulated. Finally, secondary side main features are compared in Figure 18 and Figure 19. All models have difficulties in predicting the evolution of the secondary pressure. Nevertheless, main feed water, vapor mass flow rate and steam dump behaviors are very close to the plant data.

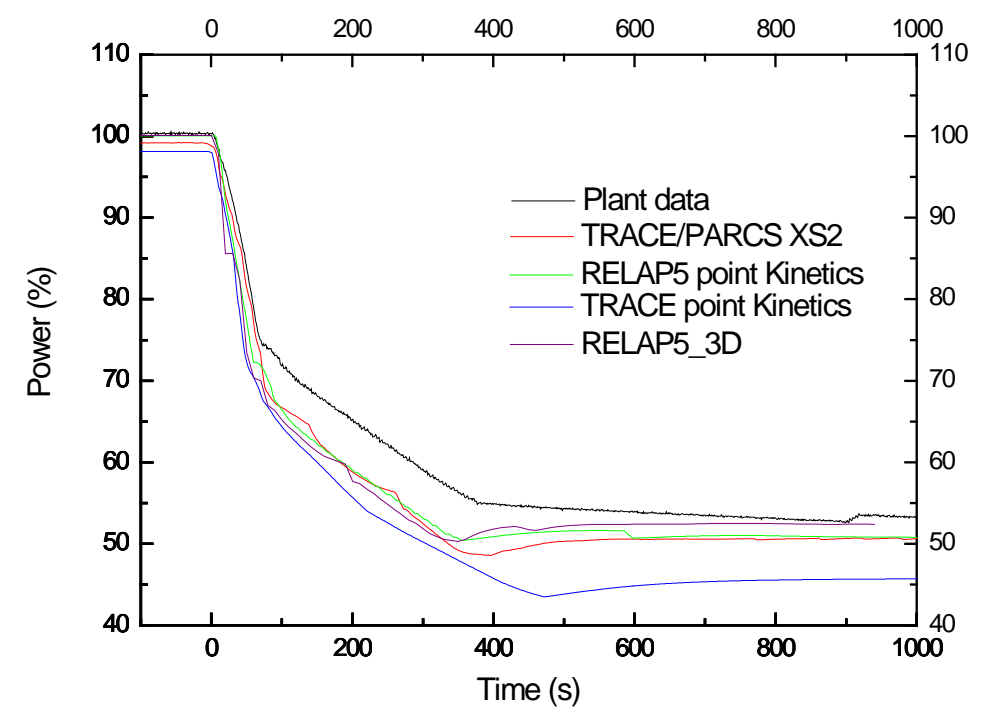

Figure 14. Total power multiple models comparison 


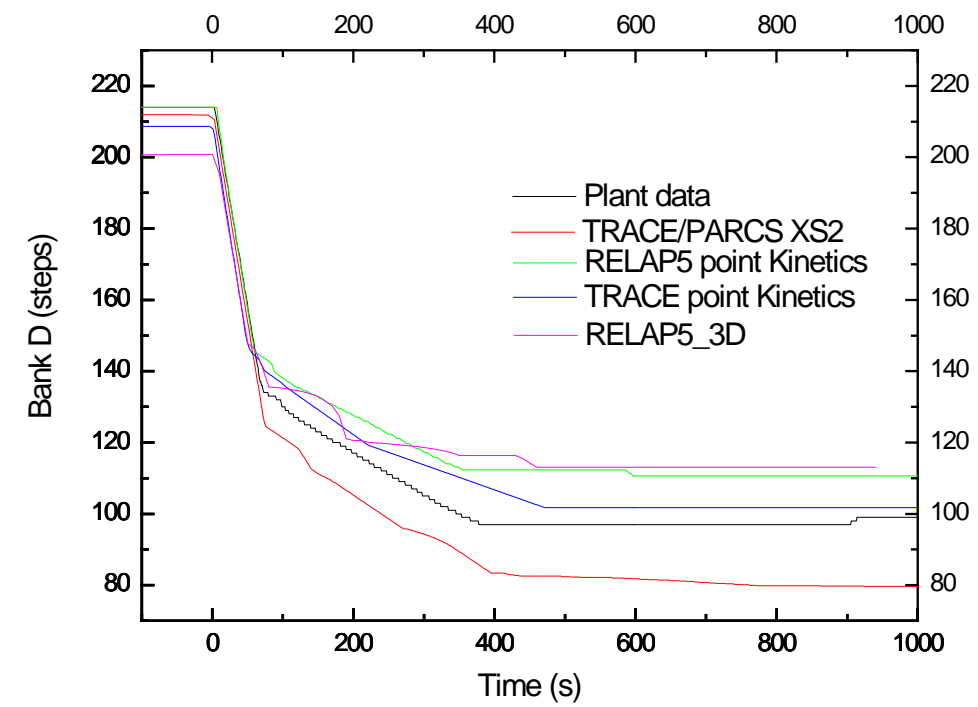

Figure 15. Control rod bank D multiple models comparison

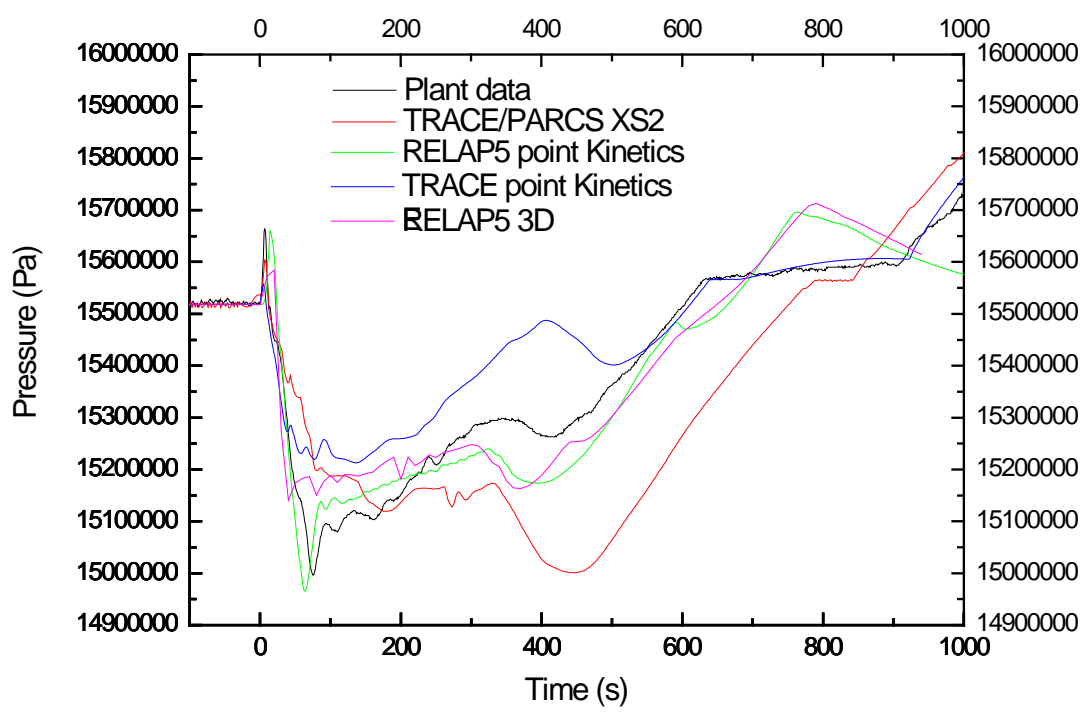

Figure 16. Pressurizer pressure multiple models comparison 


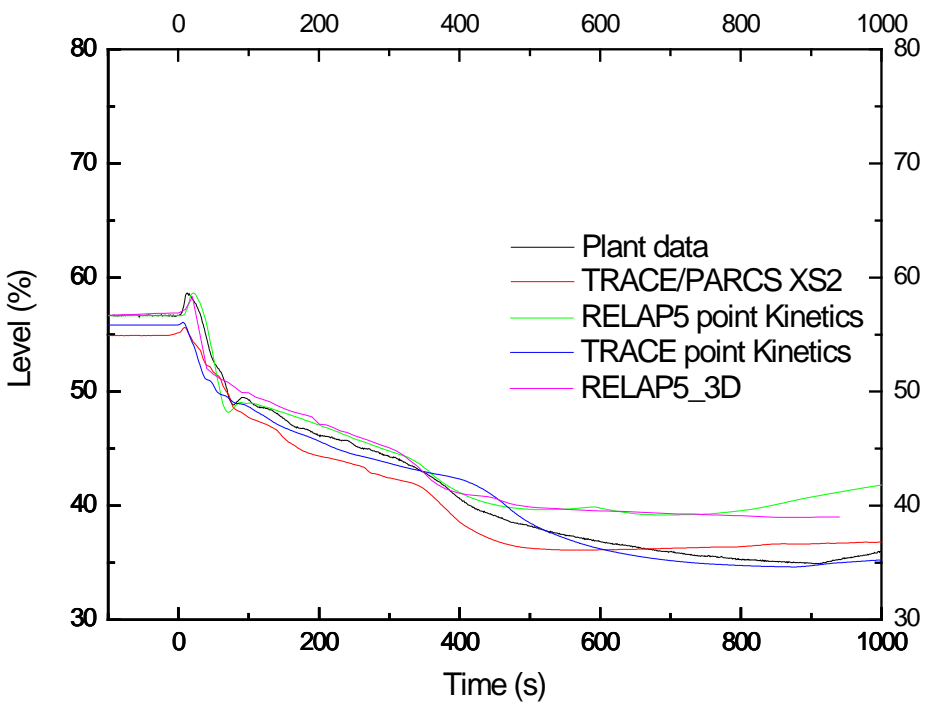

Figure 17. Pressurizer water level multiple models comparison

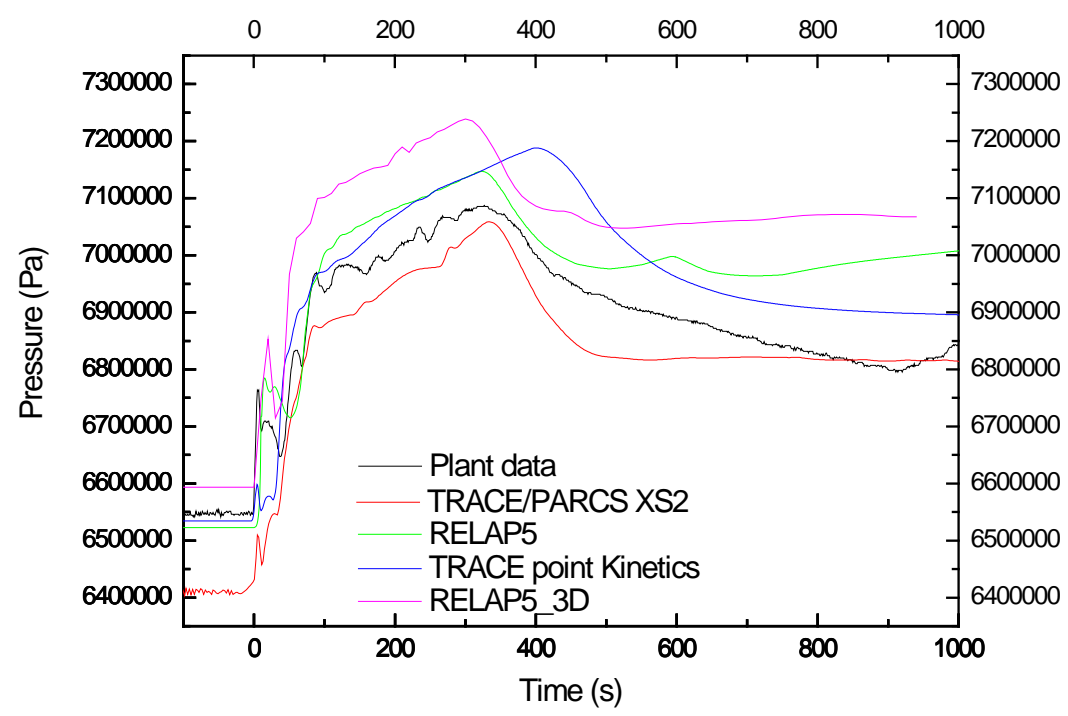

Figure 18. Secondary side SG2 pressure multiple models comparison 


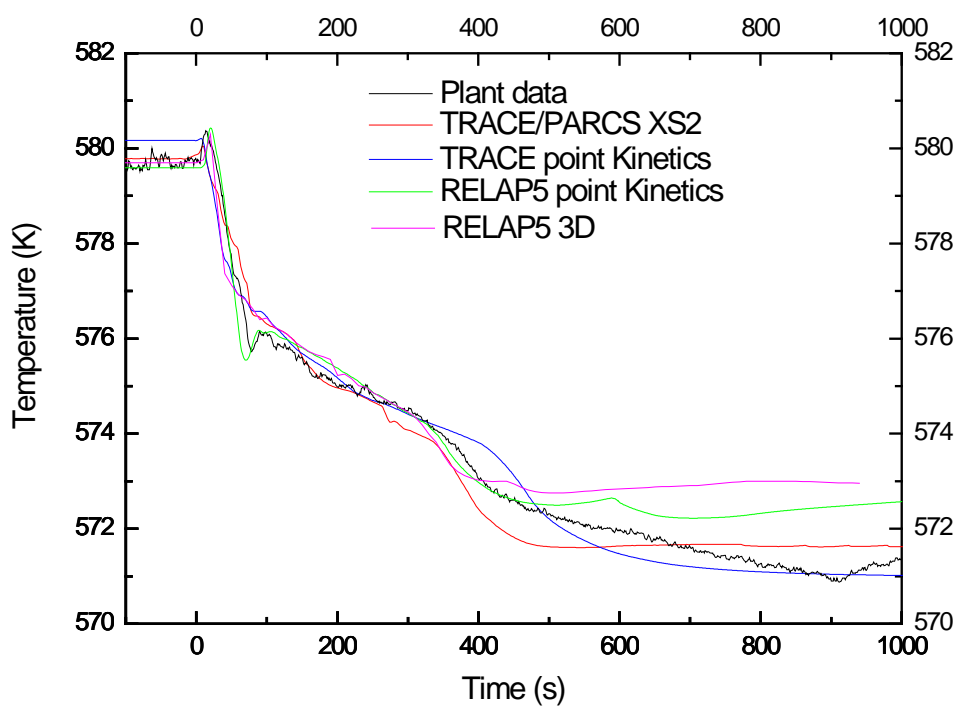

Figure 19. Loops mean temperature multiple models comparison

\section{CONCLUSIONS}

The TRACE/PARCS model has shown a good agreement with the plant data in the simulation of the $50 \%$ Loss of Load transient. The comparison with the results from other models is meaningful and helpful for the qualification of the TRACE/PARCS model. The first step in the validation of the TRACE/PARCS model is considered successful. Nevertheless, to achieve the same level of qualification of the RELAP5 model, the new model needs to be validated using a large library of cases. For 3D kinetics validation, the dynamic control rod movement is necessary in order to validate any model and calculation performed. TRACE/PARCS source code modification performed to allow logic control of the control rod banks has shown a good performance. The implementation will be useful for future use in the area of transient analysis involving relevant control rod contribution. Among these transients are other startup tests and transients, necessary for the control system adjustment, and operational transients. This new capability should be taken it into account by the developers of the codes in future released versions. The possible sources of deviations have been identified and constitute the basis of future work and developments in order to improve the model. Further model improvements are related to: XS library accuracy, control rod movement logics in TRACE, TH vessel nodalization, rod cusping correction effect, and exchange of information between the two codes. An ongoing work consist in compiling a more detailed XS library containing an assessment of uncertainties for the neutron kinetics parameters. The present model, explained in this paper, will benefit from this task in the future. 


\section{ACKNOWLEDGEMENTS}

The authors of this paper express their appreciation for the support offered by ANAV Asociación Nuclear Ascó Vandellòs in providing the plant data from Ascó NPP.

\section{REFERENCES}

[1] ENUSA. ITEC-779 Rev-2 Informe de diseño nuclear del ciclo 13 de la central nuclear Ascó II. December 1999

[2] US NRC. TRACE V5.0 THEORY MANUAL. Volume 1: Field Equations, Solution Methods, and modelling Techniques.

[3] T. Downar, Y. Xu, V. Seker, PARCS v3.0, U.S. NRC Core Neutronics Simulator "USER MANUAL" Department of Nuclear Engineering and Radiological Sciences University of Michigan Ann Arbor. December, 2009

[4] HELIOS 1.9 manuals and documentation, Studsvik Scandpower, November 2005, Norway.

[5] Y. XU T. Downar GenPMAXS-V5 Code for Generating the PARCS Cross Section Interface File PMAXS University of Michigan Dec, 2009

[6] F. Reventós, L. Batet, C. Llopis, C. Pretel, and I. Sol, "Thermal-Hydraulic Analysis Tasks for ANAV NPPs in Support of Plant Operation and Control," Science and Technology of Nuclear Installations, vol. 2008, Article ID 153858, 13 pages, 2008. doi:10.1155/2008/153858

[7] F. Reventos, L. Batet, C. Llopis, C. Pretel, M. Salvat, I. Sol, Advanced qualification process of ANAV NPP integral dynamic models for supporting plant operation and control, Nuclear Engineering and Design, Volume 237, Issue 1, January 2007, Pages 54-63, ISSN 0029-5493

[8] F. Reventós, L. Batet, C. Pretel, M. Ríos, I. Sol, Analysis of the Feed and Bleed procedure for the Ascó NPP: First approach study for operation support, Nuclear Engineering and Design, Volume 237, Issue 18, October 2007, Pages 2006-2013, ISSN 0029-5493

[9] R. Pericas ; Reventós F.; Batet L.; "Sensitivity Analyses of a hypothetical 6 inch break, LOCA in Ascó NPP using RELAP/MOD3.2." NUREG/IA-243. 2007

[10] F. Reventós, C. Llopis, L. Batet, C. Pretel, I. Sol, Analysis of an actual reactor trip operating event due to a high variation of neutron flux occurring in the Vandellòs-II nuclear power plant, Nuclear Engineering and Design, Volume 240, Issue 10, October 2010, Pages 2999-3008, SSN 0029-5493 
[11] V. Martinez-Quiroga, F. Reventos. IThe Use of System Codes in Scaling Studies: Relevant Techniques for Qualifying NPP Nodalizations for Particular Scenarios". Technical University of Catalonia, Institute of Energy Technologies, Science and Technology of Nuclear Installations, Vol. 2014, Article ID 138745, December 2013.

[12] V. Martinez-Quiroga, F. Reventos and J. Freixa. Applying UPC Scaling-Up Methodology to the LSTF PKL Counterpart Test". Technical University of Catalonia, Institute of Energy Technologies, Science and Technology of Nuclear Installations, Vol. 2014, Article ID 292916, December 2013.

[13] US Nuclear Regulatory Commission OECD Nuclear Energy Agency. "PRESSURISED WATER REACTOR MAIN STEAM LINE BREAK (MSLB) BENCHMARK, Volume I, Volume II and Volume III.

[14] Neutronics / Thermal-hydraulics Coupling in LWR Technology, Vol.1, Vol.2 and Vol.3, CRISSUE-S - WP1, WP2 and WP3. 5th EURATOM Framework Programme OECD/NEA 2004

[15] R. Pericas, K. Ivanov, F. Reventós. Comparison of Best Estimate Plus Uncertainties and Conservative Methodologies for a PWR MSLB Analysis using Coupled 3D Neutron Kinetics/Thermal-Hydraulic Code The 15th International Topical Meeting on Nuclear Reactor Thermal - Hydraulics, NURETH-15 Pisa, Italy, May 12-15, 2013

[16] R. Miró, P. Ana, T. Barrachina, J. C. Martnez-Murillo, C. Pereira, G. Verds, Universitat Politècnica de València. IImplementation of the Control Rod Movement Option by means of Control Variables in RELAP5/PARCS v2.7 Coupled Code". Division of Systems Analysis, OECD of Nuclear Regulatory Research, U.S. Nuclear Regulatory Commission, NUREG/IA 0402, July 2014. 